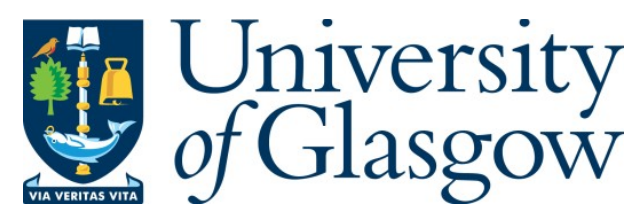

Zhang, F.-D., Lin, C.-G., Diao, S.-J., Miras, H. N. and Song, Y.-F. (2021) Direct molecular confinement in layered double hydroxides: from fundamental to advanced photo-luminescent hybrid materials. Inorganic Chemistry Frontiers, 8(5), pp. 13241333.

(doi: 10.1039/D0QI01349H)

This is the Author Accepted Manuscript.

There may be differences between this version and the published version. You are advised to consult the publisher's version if you wish to cite from it.

http://eprints.gla.ac.uk/232506/

Deposited on: 10 February 2021

Enlighten - Research publications by members of the University of Glasgow http://eprints.gla.ac.uk 


\title{
Direct Molecular Confinement in Layered Double Hydroxides: From Fundamentals to Advanced Photo-luminescent Hybrid Materials
}

\author{
Fen-Di Zhang, ${ }^{a}$ Chang-Gen Lin, ${ }^{* a}$ Shu-Jing Diao ${ }^{a}$ and Yu-Fei Song*a
}

\begin{abstract}
Two-dimensional organic-inorganic hybrid materials based on layered double hydroxides (LDHs) have drawn significant attention during the last decade. The development of such materials is usually based on the intercalation of LDHs. However, the direct intercalation of organic guest molecules into the gallery of LDHs using carbonate-intercalated LDHs as starting material is still challenging. To this end, we propose here a new approach with general applicability in the efficient decarbonation and direct intercalation of LDHs using organic acids. The intercalation mechanism has been investigated in detail using acetic acid as a proof of concept. It is demonstrated that the interlayer carbonates of LDHs are converted into carbon dioxides in the presence of acetic acid, thus leaving acetates as counter-anions within the gallery of LDHs. The feasibility of the methods has been examined using LDHs of different lateral sizes and layer compositions. As a result, various aliphatic and aromatic organic anions including carboxylates, sulfonates and phosphonates have been successfully intercalated into the galleries of LDHs. Moreover, aggregation-induced emission molecules have also been intercalated into LDHs to develop a new type of photo-luminescent hybrid materials that exhibit enhanced fluorescence and quantum yield. Therefore, this work provides a fundamentally new approach for the facile preparation of LDH hybrids and design of hybrid materials for applications in diverse fields such as energy, environment, medicine, and catalysis.
\end{abstract}

\section{Introduction}

Layered double hydroxides (LDHs), also known as hydrotalcitelike compounds, are a large class of anionic clays that can be described by the general formula of $\left[\mathrm{M}^{2+}{ }_{1-x} \mathrm{M}^{3+} \times(\mathrm{OH})_{2}\right]\left(\mathrm{A}^{\mathrm{n}-}\right.$ )$_{x / n} \cdot m \mathrm{H}_{2} \mathrm{O}$, where $\mathrm{M}^{2+}$ and $\mathrm{M}^{3+}$ stand for divalent and trivalent metal cations located in the positively charged host layers and $\mathrm{A}^{\mathrm{n}-}$ represents the interlayer counter-anions. ${ }^{1-3}$ Due to the versatility of $\mathrm{LDHs}$ in structural composition and the supramolecular interactions between the LDH host layer and the interlayer anions, LDHs have been widely explored in the fields of catalysis, ${ }^{4-6}$ sensing, ${ }^{7,8}$ drug/gene delivery, ${ }^{9,10}$ polymer nanocomposite, ${ }^{11,12}$ etc.

Among the LDHs of different inorganic and organic anions, carbonate-intercalated LDHs are the most frequently synthesized ones in the industry and have been used in large scale applications. However, because of the high affinity of carbonates towards the $\mathrm{LDH}$ host layers, ${ }^{13}$ the direct intercalation of organic anions into the gallery of LDHs using carbonate-intercalated LDHs as starting material is highly chalengin gand costly for large scale aplications. An alternative way to obtain such organic-inorganic hybrids is the utilization of the nitrate- or chloride-intercalated LDHs as starting material for anion exchange. ${ }^{14-18}$ The nitrate- or chloride-LDHs can be prepared by the de-carbonation of carbonate-LDHs in water ${ }^{19-}$ ${ }^{23}$ or alcohols. ${ }^{24,25}$ Due to the weak interactions between the nitrates/chlorides and the LDH host layers, the interlayer anions can be easily exchanged in the presence of excessive organic anions. Surfactants such as sodium dodecyl sulfate (SDS) or water/alcohol mixtures may be used for those organic anions of limited water-solubility. ${ }^{15,18}$ Other methods to prepare LDHbased hybrids include the co-precipitation of organic anions during the synthesis of $\mathrm{LDHs}^{26-28}$ and the calcinationreconstruction of $\mathrm{LDH}$ platelets in the aqueous solution of organic anions. ${ }^{29}$ The direct intercalation of organic anions into the gallery of LDHs was also reported. ${ }^{30}$ It was achieved by directly replacing the interlayer carbonates by carboxylic acids in 1-propanol/ toluene mixture under solvothermal treatment at $120{ }^{\circ} \mathrm{C}$ for 12 hours. However, this method is not versatile enough when compared with the intercalations in aqueous media.

Herein we report a new approach for the direct intercalations of LDHs by using organic acids as proton sources (Scheme 1). The intercalation, performed in methanol solution, is considered a metathesis reaction, in which the interlayer carbonate annions are effectively converted into carbon dioxide molecules in the presence of organic acids, thereby leaving the corresponding organic anions within the interlayers of LDHs to balance the charge of the host layers. The LDH platelets exhibit high acid-resistance during the reaction

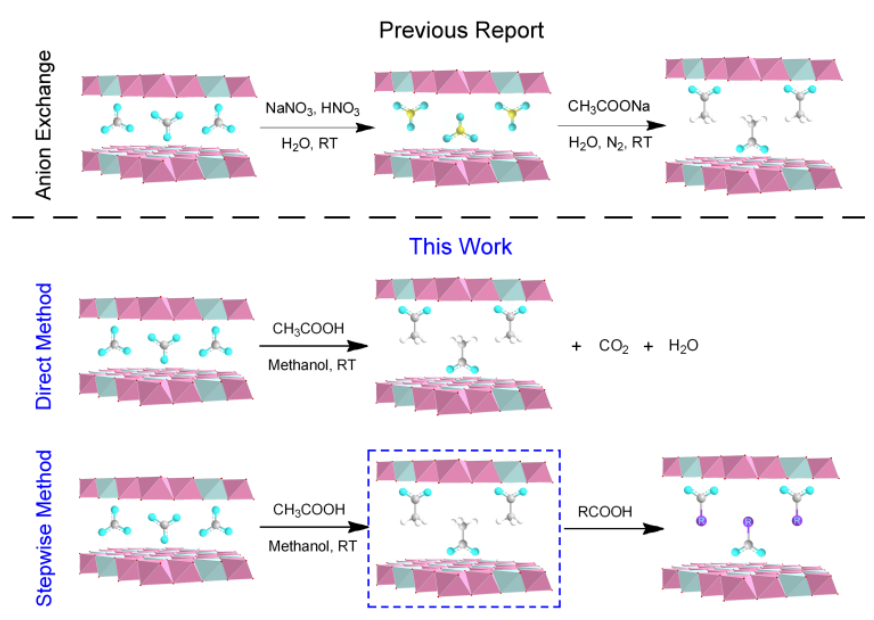

Scheme 1 Schematic representation of the previously reported anion exchange method, and the methods reported in this work. The $\left\{\mathrm{MgO}_{6}\right\}$ octahedron is shown in purple and $\left\{\mathrm{AlO}_{6}\right\}$ in light blue, and the interlayer carbonates, nitrates and organic carboxylates are shown in ball-and-stick mode. Acetic acid is selected as a representative for the direct method. The blue dotted box in the stepwise method indicates the acetate-intercalated $\mathrm{LDHs}$ are intermediates during the reaction and are used directly for the next step without separation. The interlayer water molecules of LDHs are omitted for clarity. 
and maintain their high crystallinity after intercalation. The reaction mechanism has been investigated on the basis of different types of LDHs and organic acids. As a proof of concept, acetic acid is selected for the detailed investigation of the method and the general applicability of the approach is extended to other organic acids. Consequently, various aliphatic and aromatic organic anions including carboxylates, sulfonates, and phosphonates have been successfully intercalated into the galleries of LDHs. Furthermore, a new type of photoluminescent LDH hybrids based on the methods has been prepared by intercalating aggregation-induced emission molecules into the gallery of LDHs, leading to hybrid materials of increased fluorescence intensity and quantum yield.

\section{Experimental Section}

\section{Materials}

Organic acids used in this work were purchased from Shanghai Energy Chemical and used as received. Inorganic chemicals were purchased from Beijing Chemical Works and used without further purification. $2-3 \mu \mathrm{m},{ }^{31} 250-500 \mathrm{~nm},{ }^{32}$ and $25-50 \mathrm{~nm}^{33}$ $\mathrm{Mg}_{2} \mathrm{Al}-\mathrm{LDHs}$ were synthesized according to published procedures and denoted as $\mathrm{Mg}_{2} \mathrm{Al}-\mathrm{L}, \mathrm{Mg}_{2} \mathrm{Al}-\mathrm{M}$, and $\mathrm{Mg}_{2} \mathrm{Al}-\mathrm{S}$, respectively (Fig. S1). $\mathrm{Zn}_{2} \mathrm{Al}-\mathrm{LDHs}, \mathrm{Co}_{2} \mathrm{Al}-\mathrm{LDHs}$, and $\mathrm{Ni}_{2} \mathrm{Fe}-\mathrm{LDHs}$ were prepared following the urea method. ${ }^{18}$ Tris-LDHs were synthesized according to the reported procedure. ${ }^{34}$ All the LDHs used in this work are carbonated unless otherwise mentioned. Tetraphenylethylene carboxylic acid (TPE, 4-(1,2,2triphenylvinyl)benzoic acid) was synthesized following the literature method and was fully characterized prior its use. ${ }^{35}$

\section{Characterizations}

FT-IR spectra were recorded on a Bruker Vector 22 infrared spectrometer using $\mathrm{KBr}$ pellet method. Solid-state ${ }^{13} \mathrm{C} N M R$ experiments were carried out on a Bruker Avance $300 \mathrm{MHz}$ solid-state spectrometer equipped with a commercial $5 \mathrm{~mm}$ MAS NMR probe. Powder X-ray diffraction (PXRD) patterns were recorded on a Rigaku XRD-6000 diffractometer under $\mathrm{Cu}_{\mathrm{Ka}}$ radiation $(\lambda=0.1542 \mathrm{~nm})$ at a scanning rate of $2^{\circ} \mathrm{min}^{-1}$. Scanning electron microscopy (SEM) images were obtained using a Zeiss Supra 55 SEM. Transmission electron microscopy (TEM) was carried out on a FEI Tecnai G2 F20 microscope. High-resolution transmission electron microscopy (HRTEM) images were obtained on a JEOL JEM-2010 electron microscope. Atomic force microscopy (AFM) was performed on a VEECO Multimode nanoscope Illa instrument. Gas chromatography-mass spectrometry (GC-MS) was carried out on a Shimadzu GCMSQP2010 system. Fluorescence spectra were recorded on a Hitachi F-7000 luminescence spectrometer with a Xe lamp as the excitation source. Fluorescence lifetime and absolute quantum yield were obtained on a FLS-980 steadystate/transient fluorescence spectrometer.

\section{General procedure for the intercalation}

The direct method: $100 \mathrm{mg} \mathrm{Mg} 2 \mathrm{Al}-\mathrm{LDHs}(0.4105 \mathrm{mmol}$ ) were dispersed in $45 \mathrm{~mL}$ of methanol under vigorous stirring. To this solution the desired amount of organic acid (see Table S1) in 5 $\mathrm{mL}$ methanol was added. The resulting mixture was stirred to react for 2 hours under nitrogen, and then set to centrifuge. The product was washed several times with methanol, and dried in vacuum.

The stepwise method: $100 \mathrm{mg} \mathrm{Mg} 2 \mathrm{Al}-\mathrm{LDHs}(0.4105 \mathrm{mmol})$ were dispersed in $45 \mathrm{~mL}$ of methanol under vigorous stirring. To this solution glacial acetic acid (141 $\mu \mathrm{L}, 2.463 \mathrm{mmol}$ ) in $5 \mathrm{~mL}$ methanol was added. The resulting mixture was stirred to react for 2 hours under nitrogen, and then another solution of target organic acid in $5 \mathrm{~mL}$ methanol (see Table S1) was added. The mixture was reacted for additional 2 hours under nitrogen, and then set to centrifuge. The product was collected, washed with methanol, and dried in vacuum.

\section{Results and Discussion}

\section{The intercalation of acetates}

Due to the strong electrostatic interactions between the LDH host layers and the interlayer carbonates, the direct anion exchange of carbonates into acetates is is highly challenging. An alternative way to prepare the pure phase of acetateintercalated LDHs is to synthesize the chloride-intercalated LDHs first, and then conduct anion exchange in the presence of excessive sodium acetates. ${ }^{14}$ Another route to prepare acetateLDHs is the in situ hydrolysis of acetamide during hydrothermal synthesis of LDHs. ${ }^{36}$ In our approach, the acetate-intercalated LDHs are obtained by introducing acetic acid directly to the reaction mixture to convert the interlayer carbonates into carbonic acid, which then decompose to carbon dioxide and water (Scheme 1, the Direct Method). The synthesis is straightforward. Addition of glacial acetic acid into the suspension of $\mathrm{Mg}_{2} \mathrm{Al}-\mathrm{L}$ in methanol followed by stirring for 2 hours, the acetate-intercalated LDHs, $\mathrm{Mg}_{2} \mathrm{Al}-\mathrm{L}-\mathrm{AcO}$, can be obtained in high yield (92\%). To prove our hypothesis that the interlayer carbonates were eventually converted into carbon dioxides, GC-MS was used to monitor the composition of the released gas during the reaction. As expected, carbon dioxide was detected once the reaction was started and its concentration reached its highest value within 5 minutes (Fig. S2A). No carbon dioxide was detected after 20 minutes of reaction, suggesting the de-carbonation has been completed at this point. We also tried to use nitrate-intercalated LDHs as starting material to perform the intercalation reaction which was unsuccessful (Fig. S2B). This is due to the fact that the acidity of acetic acid ( $\mathrm{pKa}=4.76$ ), is sufficient for the substitution of a weaker acid like carbonic acid ( $p K a=6.38$ ) but not enough in the case of a stronger acid such as nitric acid ( $p K a$ $=-2.0$ ). 

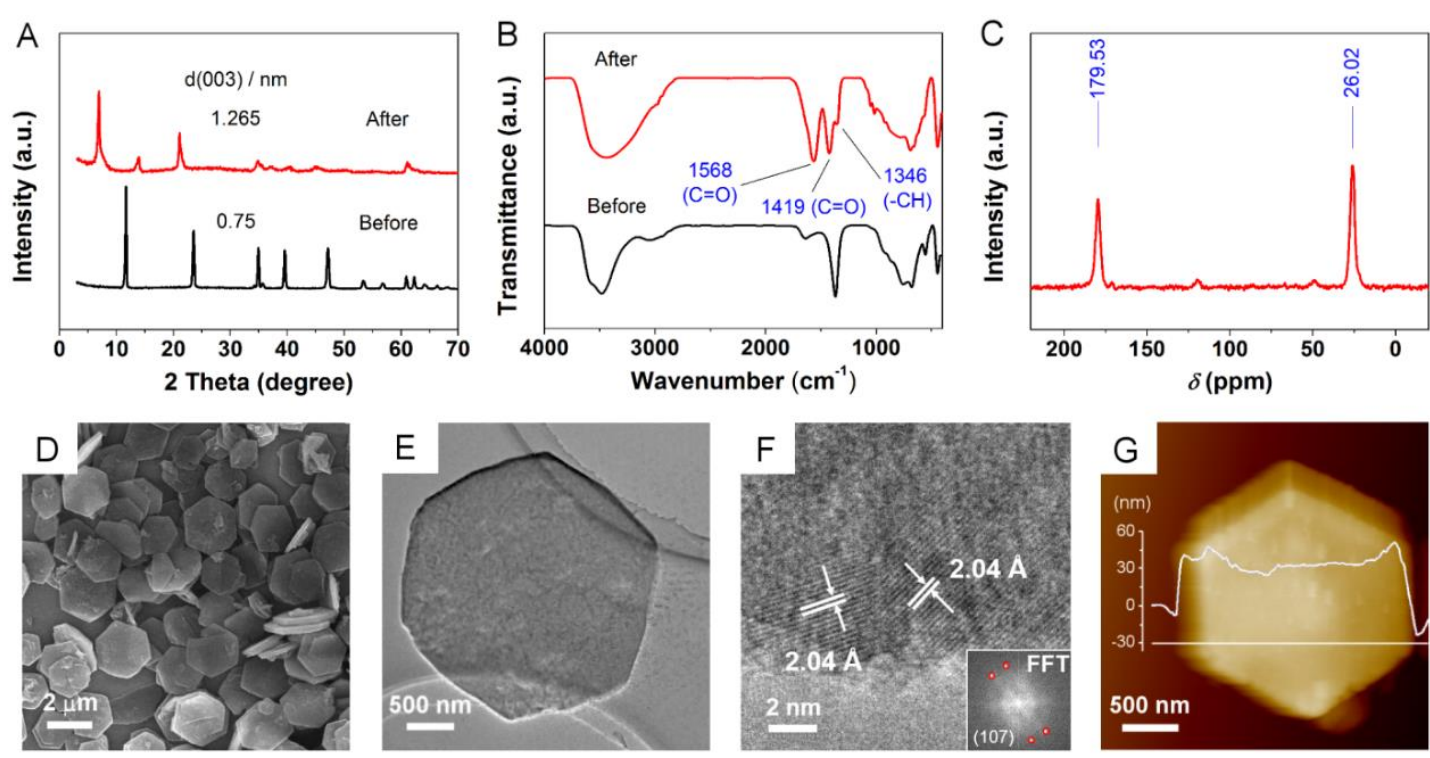

Fig. $1 \mathrm{~A}$ ) The powder XRD patterns of $\mathrm{Mg}_{2} \mathrm{Al}-\mathrm{L}-\mathrm{AcO}$ (After) and $\mathrm{Mg}_{2} \mathrm{Al}-\mathrm{L}$ (Before), B) the FT-IR spectra of $\mathrm{Mg}_{2} \mathrm{Al}-\mathrm{L}-\mathrm{AcO}$ (After) and Mg $\mathrm{Al}-\mathrm{L}$ (Before), C) the solid-state ${ }^{13} \mathrm{C}$ NMR spectrum of $\left.\mathrm{Mg}_{2} \mathrm{Al}-\mathrm{L}-\mathrm{AcO}, \mathrm{D}\right)$ the SEM micrograph of $\left.\mathrm{Mg}_{2} \mathrm{Al}-\mathrm{L}-\mathrm{AcO}, \mathrm{E}\right)$ the TEM micrograph of $\mathrm{Mg}_{2} \mathrm{Al}-\mathrm{L}-\mathrm{AcO}, \mathrm{F}$ ) the HR-TEM image of $\mathrm{Mg}{ }_{2} \mathrm{Al}-\mathrm{L}-\mathrm{AcO}$ with the inset of FFT pattern, and F) the AFM of $\mathrm{Mg}_{2} \mathrm{Al}-\mathrm{L}-\mathrm{ACO}$ : the height of the platelet is indicated on the image.

The pure phase of the obtained $\mathrm{Mg}_{2} \mathrm{Al}-\mathrm{L}-\mathrm{AcO}$ is examined by powder XRD. As shown in Fig. $1 \mathrm{~A}$, the characteristic (003), (006) and (009) peaks of LDHs are well-displayed, and shift into lower degree region when compared with those of $\mathrm{Mg}_{2} \mathrm{Al}-\mathrm{L}$, suggesting the increase of the interlayer spacing. The basal distance is calculated to be $1.26 \mathrm{~nm}$ after acetate intercalation. Considering the layer height of LDH platelet (ca. $0.48 \mathrm{~nm}$ ) and the length of an acetate molecule ( $c a .0 .36 \mathrm{~nm}$ ), a bilayer interlayer arrangement of acetates is suggested. ${ }^{37} \mathrm{The} \mathrm{Mg}_{2} \mathrm{Al}-\mathrm{L}-$ $\mathrm{AcO}$, similar to the previously reported ones, ${ }^{36,37}$ is sensitive to humid atmosphere. The basal distance of $\mathrm{Mg}_{2} \mathrm{Al}-\mathrm{L}-\mathrm{AcO}$ decreases to $0.898 \mathrm{~nm}$ at relative humidity $(\mathrm{RH})$ of $0 \%$, and bounces back to $1.265 \mathrm{~nm}$ when restored at RH of $98 \%$ (Fig. $\mathrm{S} 2 \mathrm{C})$. Such changes reflect that the interlayer acetates transfer from a bilayer arrangement into a single-layer mode during dehydration process and recover to bilayer upon hydration. In the FT-IR spectrum, the peak of carbonate $\left(c a .1380 \mathrm{~cm}^{-1}\right)$ disappears after acetate intercalation, and three new peaks show up at ca. 1568, 1419, and $1346 \mathrm{~cm}^{-1}$, which can be assigned to the asymmetric and symmetric stretching bands of carboxylate $(\mathrm{C}=\mathrm{O})$ and the bending vibration of the methyl group (C-H), respectively (Fig. 1B). Since the stretching band of carboxylic acid usually appears above $1700 \mathrm{~cm}^{-1}$, it is safe to state here that there is no absorbed acetic acid on the surface or within the layers of LDHs. The complete conversion of carbonates into acetates is further proved by solid-state ${ }^{13} \mathrm{C}$ NMR (Fig. 1C). Signals at 26.02 and 179.53 ppm are attributed to the carbon atoms of $-\mathrm{CH}_{3}$ and $-\mathrm{C}=\mathrm{O}$ of acetate, respectively. Carbonates, which usually appear at $170 \mathrm{ppm}, 12$ are not observed in the spectrum. The SEM and TEM micrographs show that the $\mathrm{Mg}_{2} \mathrm{Al}-\mathrm{L}-\mathrm{AcO}$ preserves the morphology of LDHs and has a hexagonal plate-like structure (Fig. 1D and $1 \mathrm{E}$ ). We also used water as solvent to conduct the acetate intercalation reaction (Fig. S2D). However, only a very small fraction of $\mathrm{Mg}_{2} \mathrm{Al}-\mathrm{L}-\mathrm{AcO}$ was detected by powder XRD and nearly a $40 \%$ of mass loss was observed. These results demonstrate the importance of solvent in the intercalation process and the high acid-tolerance of LDHs in methanol. The crystallinity of $\mathrm{Mg}_{2} \mathrm{Al}-$ L-AcO was confirmed by HR-TEM. Lattice fringes can be clearly observed on the surface of $\mathrm{Mg}_{2} \mathrm{Al}-\mathrm{L}-\mathrm{AcO}$ (Fig. 1F). Selective area electron diffraction pattern in the FFT mode shows that the exposed lattice fringe belongs to the (107) lattice plane with a spacing of $2.04 \AA$. The surface smoothness of $\mathrm{Mg}_{2} \mathrm{Al}-\mathrm{L}-\mathrm{AcO}$ is verified by AFM measurement, which shows a nearly consistent platelet height of ca. $60 \mathrm{~nm}$ (Fig. 1G).

To examine the general applicability of the acetate intercalation method, we investigated the acetate interacalation process using LDHs of different sizes and compositions. In the case of $\mathrm{Mg}_{2} \mathrm{Al}-\mathrm{LDH}$, we conluded that the intercalation process becomes easier as the size of the LDHs decreases (Table S1). 

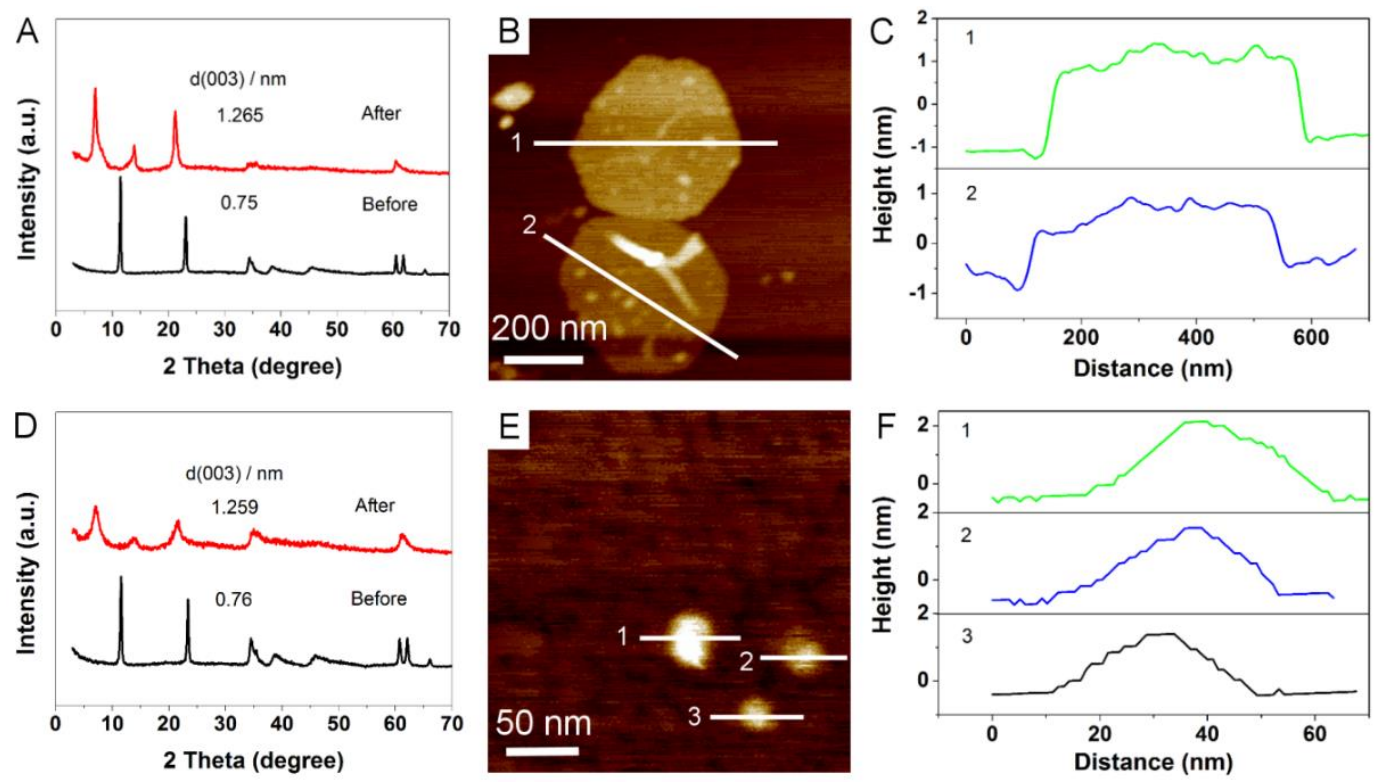

Fig. $2 \mathrm{~A}$ ) The powder XRD patterns of $\mathrm{Mg}_{2} \mathrm{Al}-\mathrm{M}-\mathrm{AcO}$ (After) and $\mathrm{Mg}_{2} \mathrm{Al}-\mathrm{M}$ (Before), B) the AFM of $\mathrm{Mg}_{2} \mathrm{Al}-\mathrm{M}-\mathrm{AcO}$, C) the corresponding layer height of Mg $\mathrm{Al}-\mathrm{M}-\mathrm{AcO}$, D) The powder XRD patterns of $\mathrm{Mg}_{2} \mathrm{Al}-\mathrm{S}-\mathrm{AcO}$ (After) and $\mathrm{Mg}_{2} \mathrm{Al}-\mathrm{S}$ (Before), $\mathrm{E}$ ) the AFM of $\mathrm{Mg}_{2} \mathrm{Al}-\mathrm{S}-\mathrm{AcO}$, and $\mathrm{F}$ ) the corresponding layer height of $\mathrm{Mg}_{2} \mathrm{Al}-\mathrm{S}-\mathrm{AcO}$.

It requires 6 equivalents of acetic acid in the case of $\mathrm{Mg}_{2} \mathrm{Al}-\mathrm{L}$ to carry out the intercalation, while only 3 equivalents for $\mathrm{Mg}_{2} \mathrm{Al}-$ $\mathrm{M}$ and 2.5 equivalents for $\mathrm{Mg}_{2} \mathrm{Al}-\mathrm{S}$. This can be explained by the fact that smaller-size LDHs are easily dispersed in methanol and their carbonate occupied galleries are more accessible by the acetic acid molecules. Powder XRD measurements demonstrated that both $\mathrm{Mg}_{2} \mathrm{Al}-\mathrm{M}$ and $\mathrm{Mg}_{2} \mathrm{Al}-\mathrm{S}$ have been successfully intercalated by acetates. The basal distance of $\mathrm{Mg}_{2} \mathrm{Al}-\mathrm{M}-\mathrm{AcO}$ is calculated to be $1.265 \mathrm{~nm}$, the same as that of $\mathrm{Mg}_{2} \mathrm{Al}-\mathrm{L}-\mathrm{AcO}$; while the basal distance of $\mathrm{Mg}_{2} \mathrm{Al}-\mathrm{S}-\mathrm{AcO}$ (1.259 $\mathrm{nm}$ ) is slightly smaller (Fig. 2A and 2D). These basal distances reflect the bilayer arranged acetates in both $\mathrm{Mg}_{2} \mathrm{Al}-\mathrm{M}-\mathrm{AcO}$ and $\mathrm{Mg}_{2} \mathrm{Al}-\mathrm{S}-\mathrm{AcO}$. The water swellability of $\mathrm{Mg}_{2} \mathrm{Al}-\mathrm{M}-\mathrm{AcO}$ is better when compared the one observed in the case of $\mathrm{Mg}_{2} \mathrm{Al}-\mathrm{L}-\mathrm{AcO}$ (Fig. S3). Stable and translucent colloidal suspensions of $\mathrm{Mg}_{2} \mathrm{Al}-$ $\mathrm{M}-\mathrm{AcO}$ were formed at concentrations of $1 \mathrm{mg} \mathrm{mL}^{-1}$ and $10 \mathrm{mg}$ $\mathrm{mL}^{-1}$, while viscous gel was formed at higher concentrations (20 $\mathrm{mg} \mathrm{mL}^{-1}$ ). AFM result showed that $\mathrm{Mg}_{2} \mathrm{Al}-\mathrm{M}-\mathrm{AcO}$ retained its hexagonal plate-like morphology with a height profile of 1.2 $2.5 \mathrm{~nm}$ (Fig. $2 \mathrm{~B}$ and $2 \mathrm{C}$ ). This indicates that $\mathrm{Mg}_{2} \mathrm{Al}-\mathrm{M}-\mathrm{AcO}$ are delaminated into single- or double-layer moieties in water. Similar results are also found in the case of $\mathrm{Mg}_{2} \mathrm{Al}-\mathrm{S}$-AcO (Fig. $2 \mathrm{E}$ and $2 \mathrm{~F}$ ). $\mathrm{Mg}_{2} \mathrm{Al}-\mathrm{S}-\mathrm{AcO}$ can be partially delaminated into a few layers as suggested by the layer height of nearly $2 \mathrm{~nm}$.

The acetate intercalations were also performed for LDHs of different layer compositions such as $\mathrm{Zn}_{2} \mathrm{Al}-\mathrm{LDHs}, \mathrm{Ni}_{2} \mathrm{Fe}-\mathrm{LDHs}$, and $\mathrm{CO}_{2} \mathrm{Al}-\mathrm{LDH}$. Powder XRD measurements reveal that all these LDHs can be successfully intercalated with acetates using the direct method (Fig. S4A-C). The basal distances found to be around $0.90 \mathrm{~nm}$ at $\mathrm{RH}$ of $0 \%$, which is close to that of the singlelayer arranged $\mathrm{Mg}_{2} \mathrm{Al}-\mathrm{L}-\mathrm{AcO}(0.898 \mathrm{~nm})$. However, the crystallinity of these LDHs after intercalation is not optimal, especially in the cases of $\mathrm{Ni}_{2} \mathrm{Fe}-\mathrm{LDHs}$ and $\mathrm{CO}_{2} \mathrm{Al}-\mathrm{LDH}$. The interlayer carbonates of covalently modified Tris-LDHs can also be converted into acetates (Fig. S4D). The basal distance of
$1.271 \mathrm{~nm}$ is similar to that of $\mathrm{Mg}_{2} \mathrm{Al}-\mathrm{L}-\mathrm{AcO}(1.265 \mathrm{~nm})$. Tris-LDHs, due to the nanoscale particle size $(10-25 \mathrm{~nm})$ and weakened interlayer interactions, ${ }^{34}$ can be easily dispersed in water when freshly prepared. However, the swelling and re-dispersing in water are found to be difficult once the samples are dried (Fig. S5A). After the exchange of interlayer carbonates by acetates, the Tris-LDHs-AcO can form transparent solutions in water with typical Tindall effect (Fig. S5B). At a high concentration of $25 \mathrm{mg}$ $\mathrm{mL}^{-1}$, Tris-LDHs-AcO turned immediately to transparent gel when water is introduced (Fig. S5C). These findings indicate that Tris-LDHs-AcO possess superior water swelling ability when compared with its un-modified $\mathrm{Mg}_{2} \mathrm{Al}$-LDHs counterparts, and can be easily delaminated in water even at high concentrations.

\section{The intercalation of other carboxylates}

The successful intercalation of acetates into LDHs using acetic acid as starting material encouraged us to investigate the intercalations of other organic carboxylates and explore the factors that affect the intercalation process. As such, various carboxylic acids, both aliphatic and aromatic, were investigated. Propionic acid, acrylic acid, and $n$-butyric acid were first selected to study the effect of alkyl chain length on the intercalation process. Employing the direct method, propionates and acrylates are easily intercalated into the galleries of $\mathrm{Mg}_{2} \mathrm{Al}-\mathrm{L}$, leading to basal distances of 1.406 and $1.338 \mathrm{~nm}$, respectively (Fig. 3A). These distances are similar to those prepared by anion exchange method. ${ }^{14,38}$ FT-IR spectra confirm that all the interlayer carbonates of $\mathrm{Mg}_{2} \mathrm{Al}-\mathrm{L}$ have been converted into carboxylates (Fig. 3B). For propionateintercalated $\mathrm{Mg}_{2} \mathrm{Al}-\mathrm{L}$, the asymmetric and symmetric stretching vibrations of carboxylate can be found at 1565 and $1420 \mathrm{~cm}^{-1}$, respectively. In the case of acrylate-intercalated $\mathrm{Mg}_{2} \mathrm{Al}-\mathrm{L}$, these vibrations are shown at 1558 and $1430 \mathrm{~cm}^{-1}$, respectively. The $\mathrm{C}=\mathrm{C}$ stretching band of acrylate is observed at $1640 \mathrm{~cm}^{-1} . n$ Butyric acid, though its pKa (4.82) is close to propionic acid's 
(4.87), was found to be more chalenging to perform the intercalation, suggesting that the direct method may not be as efficient in the case of carboxylates with long alkyl chains.
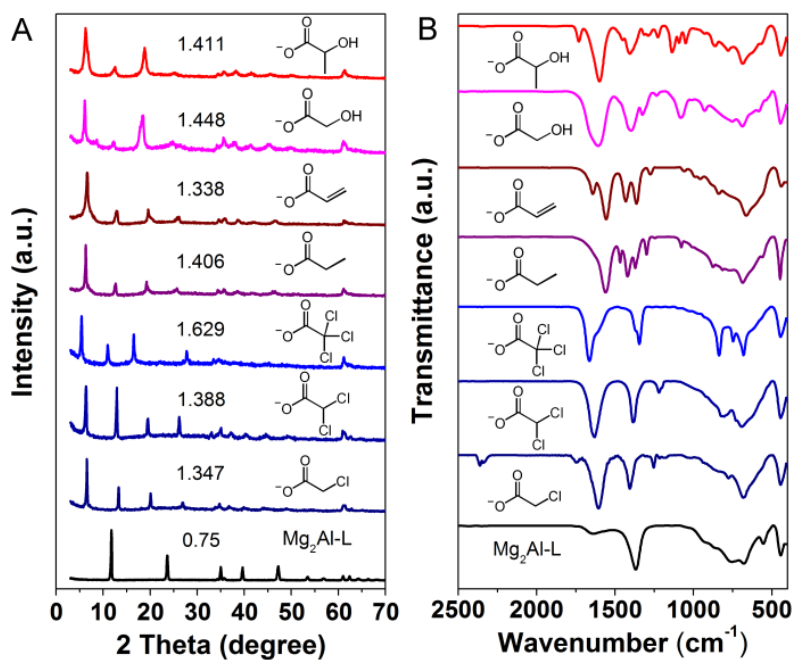

Fig. $3 \mathrm{~A}$ ) The powder XRD patterns and B) the FT-IR spectra of $\mathrm{Mg}_{2} \mathrm{Al}-\mathrm{L}$ intercalated with different aliphatic carboxylates. The basal distances of intercalated $\mathrm{Mg}_{2} \mathrm{Al}-\mathrm{L}$ and the molecular structures of the carboxylates are indicated.

The substitute effects of acetic acid on intercalations are complex. It is demonstrated that chloroacetates and dichloroacetates can be easily intercalated into the galleries of $\mathrm{Mg}_{2} \mathrm{Al}-\mathrm{L}$ by the direct method; while trichloroacetates and glycolates can not, even when excessive amounts of acids were used. Comparing the molecular structures of chloroacetic acid, dichloroacetic acid, and trichloroacetic acid, the only difference lies in the number of chloride substitutes. Increasing the number of chlorides, although resulting in stronger acidity, increases the size of the acid. It is therefore shown that the increase of molecular size counterproductive for the intercalation process. In the case of glycolic acid, has a similar molecular length and a stronger acidity when compared with propionic acid (Table S1). The fact that propionates can be readily intercalated into $\mathrm{Mg}_{2} \mathrm{Al}-\mathrm{L}$ suggests that the effect of molecular length and pKa are not the only crucial parameters in the intercalation process. The unsuccessful intercalation of glycolate is thought to be caused by the hydroxide group, which might form intermolecular hydrogen bonding with the carboxylic acid group which leads to dimerization and consequently increase of the molecular size. This observation is further confirmed by the Lactic acid, which also possesses a hydroxide group and was also prevented the intercalation using the direct method.

Since we hypothesized that the molecular size seems to prevent the intercalations of these carboxylates, we envisaged that increasing the basal distance of LDHs might make it possible. Therefore, a stepwise method was proposed (Scheme 1). The first step of this method is similar to the direct method, where the interlayer carbonates are converted into acetates. In the second step, the interlayer acetates are further transferred into desired carboxylates by adding corresponding carboxylic acids. The acetate-intercalated intermediate is considered to be a better candidate for the intercalation of larger acids because:
1) exhibits larger basal distance and 2) the interactions between LDH host layer and interlayer acetates are weaker when compared to the ones observed in the case of the intercalated carbonate anions. Therefore, using the stepwise method trichloroacetates, glycolates and lactates were all intercalated successfully into the galleries of $\mathrm{Mg}_{2} \mathrm{Al}-\mathrm{L}$ as which was confirmed by the powder XRD and FT-IR analyses (Fig. 3). In the case of dicarboxylic acids such as oxalic acid, propanedioic acid, and succinic acid, successful intercalations were also achieved using the stepwise method. The powder XRD analyses revealed that the interlayer dicarboxylates are arranged in a single layer mode since the calculated basal distances $(c a .1 .0 \mathrm{~nm})$ are too short for a double-layer arrangement (Fig. S6A). FT-IR spectra confirmed that all the carboxylic acid groups were converted into carboxylates with characteristic stretching bands in the range of $1625-1560 \mathrm{~cm}^{-1}$ (Fig. S6B).
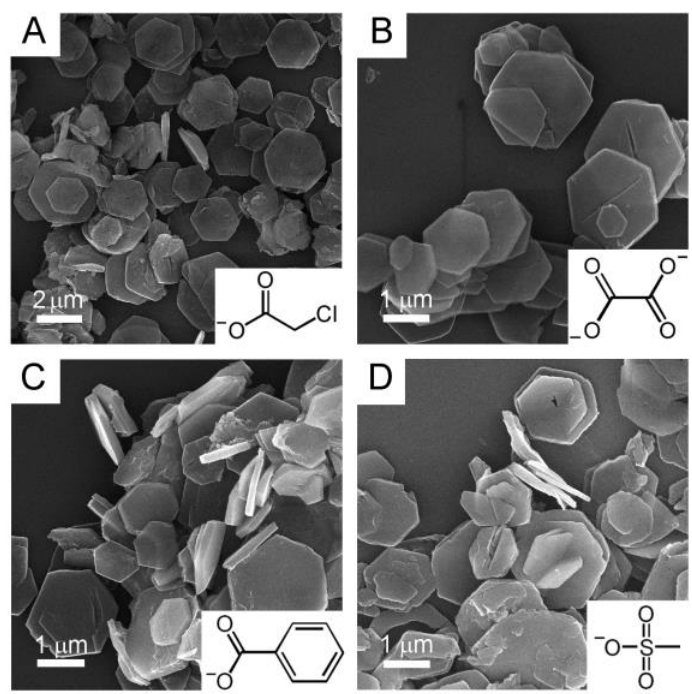

Fig. 4 The SEM micrographs of $\mathrm{Mg}_{2} \mathrm{Al}-\mathrm{L}$ intercalated with A) chloroacetates, B) oxalates, C) benzoates, and D) methanesulfonates.

Aromatic carboxylic acids were examined for their efficacy in intercalations with LDHs (Fig. S7). Benzoates were intercalated into $\mathrm{Mg}_{2} \mathrm{Al}-\mathrm{L}$ by employing the stepwise method. The basal distance was found to be $1.544 \mathrm{~nm}$ according to the powder XRD data. The asymmetric and symmetric stretching bands of carboxylates are found at 1548 and $1402 \mathrm{~cm}^{-1}$, respectively, in the FT-IR spectrum. The vibration of benzene ring $(C=C)$ is observed at $1605 \mathrm{~cm}^{-1}$. All the other aromatic carboxylates investigated in this work were intercalated successfully into the galleries of $\mathrm{Mg}_{2} \mathrm{Al}-\mathrm{L}$ following the proposed direct method. It is found that the substitutes at the para position of the benzene ring had a minor effect on the intercalation process; however the basal distances of the intercalated $\mathrm{Mg}_{2} \mathrm{Al}-\mathrm{L}$ vary from one to another. All the carboxylate-intercalated $\mathrm{Mg}_{2} \mathrm{Al}-\mathrm{L}$ hybrids, were isolated in moderate to high yields no matter the preparation method, (Table S1). The morphologies of the resulting intercalated $\mathrm{Mg}_{2} \mathrm{Al}-\mathrm{L}$ were investigated by SEM. As shown in Fig. $4 \mathrm{~A}-\mathrm{C}$, hexagonal plate-like structures were observed in all these hybrid materials, suggesting that the LDH platelets retain their structural features during the intercalation process. 


\section{The intercalation of sulfonates and phosphonates}

Carboxylate-intercalated LDHs, due to the weak interactions between the LDH host layers and the interlayer carboxylates, tend to degrade into carbonate-LDHs when exposed in air for a long time. Sulfonate-intercalation is thought to be an alternative way to avoid such problem. ${ }^{16}$ lyi et al. reported the interaction of sulfonates by adopting the anion exchange method, where perchlorate- or chloride-intercalated LDHs and sodium sulfonates were used as reactants. ${ }^{16}$ Here in this work we tried to de-carbonate $\mathrm{LDHs}$ using sulfonic acids as starting materials. The direct method was examined in our first trial; however, probably due to the larger size of the sulfonic acid group the intercalation was not successful. Therefore, the stepwise method was employed leading to the successful intercalation of various organic sulfonates into the galleries of $\mathrm{Mg}_{2} \mathrm{Al}-\mathrm{L}$ (Fig. 5).
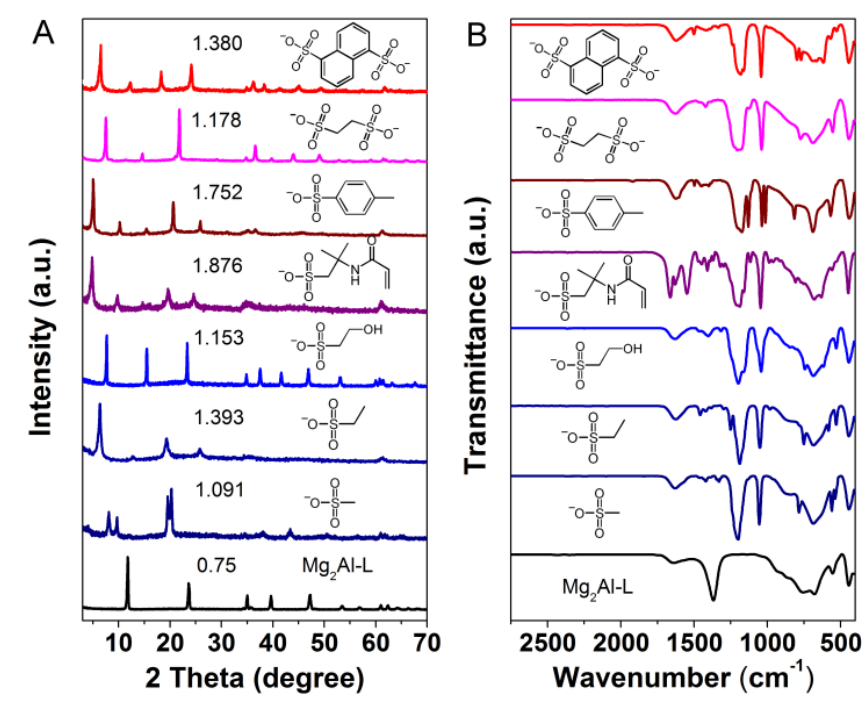

Fig. $5 \mathrm{~A}$ ) The powder XRD patterns of $\mathrm{Mg}_{2} \mathrm{Al}-\mathrm{L}$ intercalated with different sulfonates, the basal distances of intercalated $\mathrm{Mg}_{2} \mathrm{Al}-\mathrm{L}$ and the molecular structures of the sulfonates are indicated; and $\mathrm{B}$ ) the $\mathrm{FT}-\mathrm{IR}$ spectra of $\mathrm{Mg}_{2} \mathrm{Al}-\mathrm{L}$ intercalated with different sulfonates.

Taking methanesulfonate as an example, the intercalated $\mathrm{Mg}_{2} \mathrm{Al}-\mathrm{L}$ shows distinct changes in the powder XRD pattern. Two sets of XRD peaks are indexed with the typical (003) and (006) peaks shifting into lower degrees. The calculated basal distances are 1.091 and $0.914 \mathrm{~nm}$, both of which are much bigger than that of $\mathrm{Mg}_{2} \mathrm{Al}-\mathrm{L}(0.75 \mathrm{~nm})$, suggest the successful intercalation of methanesulfonates. The FT-IR spectrum of the intercalation product revealed the characteristic stretching bands of $\mathrm{S}=\mathrm{O}$ located at 1199 and $1055 \mathrm{~cm}^{-1}$, and the absence of vibrations arising from carbonate anions(Fig. 5B). The morphology of the methanesulfonate-intercalated $\mathrm{Mg}_{2} \mathrm{Al}-\mathrm{L}$ retains the typical hexagonal structure of $\mathrm{LDH}$ s as confirmed by the SEM micrograph (Fig. 4D). It should be noted that 2acrylamido-2-methyl-propane sulfonates (AMPS), which have been previously reported to be difficult to intercalate into LDHs using the anion exchange method, ${ }^{39}$ have been unambiguously intercalated into the $\mathrm{Mg}_{2} \mathrm{Al}-\mathrm{L}$ by employing the proposed stepwise method. As shown in the powder XRD pattern, the basal distance of $\mathrm{Mg}_{2} \mathrm{Al}-\mathrm{L}$ increases to $1.876 \mathrm{~nm}$ after intercalation (Fig. 5A). In FT-IR spectrum, the stretching vibrations of the amide bond are shown at 1661 (Band I) and $1547 \mathrm{~cm}^{-1}$ (Band II). The vibration of $\mathrm{C}=\mathrm{C}$ is found at $1629 \mathrm{~cm}^{-1}$, and the typical vibrations of $\mathrm{S}=\mathrm{O}$ bond are shown at 1188 and $1046 \mathrm{~cm}^{-1}$. As for the intercalation of disulfonates, the formation of a single-layer arrangement of the interlayer anions was identified, as suggested by the calculated basal distances. This finding is the same as in the cases of dicarboxylateintercalated $\mathrm{Mg}_{2} \mathrm{Al}-\mathrm{L}$ discussed above.

Going one step further, we investigated the applicability of this methoid in the case of phosphonates, which have rarely been intercalated into LDHs. Following the proposed stepwise method, phenylphosphonates and methylenediphosphonates were successfully intercalated into the galleries of $\mathrm{Mg}_{2} \mathrm{Al}-\mathrm{L}$ (Fig. S8). Unambiguous XRD peak shifts to lower degrees were observed. Additionally, the stretching vibrations of the carbonate anions are not detectable in the FT-IR spectra, and found to be replaced by the stretching bands of $\mathrm{P}=\mathrm{O}$ and $\mathrm{P}-\mathrm{O}$ centred at 1140 and $1052 \mathrm{~cm}^{-1}$, in the case of phenylphosphonate-intercalated $\mathrm{Mg}_{2} \mathrm{Al}-\mathrm{L}$, and at 1164 and $1084 \mathrm{~cm}^{-1}$, respectively, in the case of methylenediphosphonate.

\section{The Photo-luminescent LDH Hybrids}

The incorporation of functional organic molecules into the galleries of LDHs has been proved to be an effective way to develop advanced hybrid photo-luminescence and stimuliresponsive functional materials. ${ }^{3}$ To explore further the application of our methods in such area, we chose to intercalate a bulky aromatic acid, tetraphenylethylene carboxylic acid (TPE), into the gallery of $\mathrm{Mg}_{2} \mathrm{Al}-\mathrm{L}$ (Fig. 6A). TPE is a typical example of aggregation-induced emission (AIE) molecules, which exhibit fluorescence in solid state or in poor solvents, but can cause fluorescence quenching when dissolved in good solvents. ${ }^{40}$ Follwoing the proposed stepwise method, we were able to construct a TPE-intercalated LDH hybrid $\left(\mathrm{Mg}_{2} \mathrm{Al}\right.$-L-TPE), which exhibited fluorescence in both solid state and in good solvent. The successful intercalation of TPE was first confirmed by powder XRD. As depicted in Fig. 6B, the typical (00/) peaks shift into the lower degree region after intercalation, resulting in an increased basal distance of $2.707 \mathrm{~nm}$. It is worth mentioning the high crystallinity of the $\mathrm{Mg}_{2} \mathrm{Al}$-L-TPE hybrid as reflected by the narrow and sharp nature of the $(00 /)$ peaks. The FT-IR spectrum of the $\mathrm{Mg}_{2} \mathrm{Al}$-L-TPE, revealed clearly stretching vibrations of the intercalated TPE carboxylates and the absence of stretching bands that could arise from carbonates anions (Fig. 6C). The asymmetric and symmetric stretching bands of the $\mathrm{C}=\mathrm{O}$ bond were observed at 1531 and $1394 \mathrm{~cm}^{-1}$, respectively. The vibrations of $\mathrm{C}=\mathrm{C}$ bonds are shown at $1588 \mathrm{~cm}^{-1}$. SEM studies revealed that the $\mathrm{Mg}_{2} \mathrm{Al}-\mathrm{L}-\mathrm{TPE}$ hybrid retained the typical hexagonal plate-like morphology of LDHs, which is in good agreement with the powder XRD study (Fig. 6D). The fluorescence spectrum of $\mathrm{Mg}_{2} \mathrm{Al}-\mathrm{L}-\mathrm{TPE}$ is shown in Fig. 6E. Compared with the pure TPE carboxylates, the $\mathrm{Mg}_{2} \mathrm{Al}-\mathrm{L}-\mathrm{TPE}$ hybrid exhibited a substantial increase of the fluorescence intensity. This is due to the confinement effect, which 

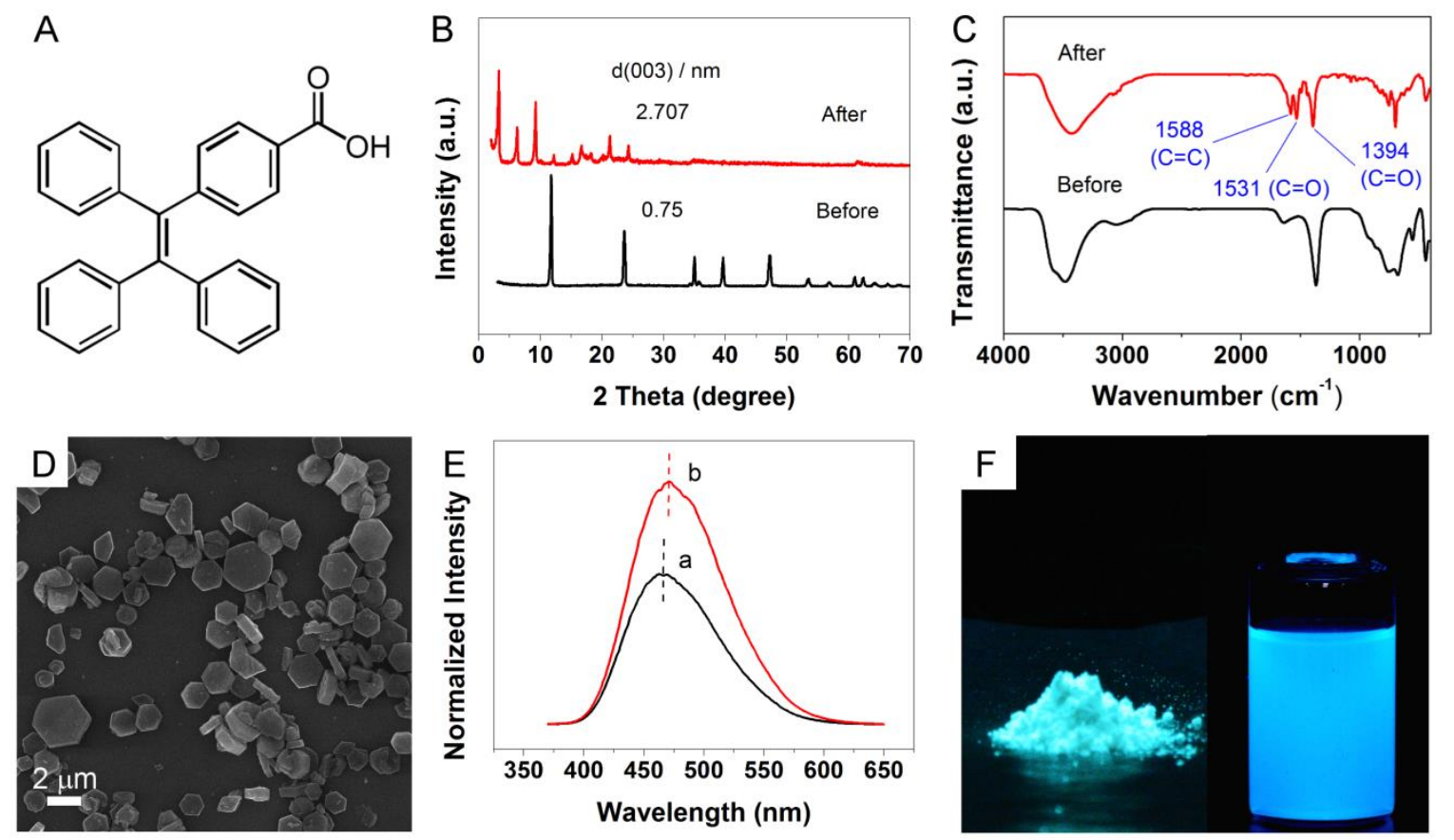

Fig. 6 A) The molecular structure of TPE, B) the powder XRD patterns of $\mathrm{Mg}_{2} \mathrm{Al}-\mathrm{L}-\mathrm{TPE}$ (After) and $\mathrm{Mg}_{2} \mathrm{Al}-\mathrm{L}$ (Before), C) the FT-IR spectra of Mg${ }_{2} \mathrm{Al}-\mathrm{L}-\mathrm{TPE}$ (After) and Mg${ }_{2} \mathrm{Al}-\mathrm{L}$ (Before), D) the SEM image of $\mathrm{Mg}_{2} \mathrm{Al}-\mathrm{L}-\mathrm{TPE}$, E) the fluorescence spectra of TPE carboxylates (a) and $\mathrm{Mg}_{2} \mathrm{Al}-\mathrm{L}-\mathrm{TPE}(\mathrm{b})$, and $\mathrm{F}$ ) the photograph of $\mathrm{Mg}{ }_{2} \mathrm{Al}-\mathrm{L}-\mathrm{TPE}$ under UV irradiation in powder state (left) and dispersed in methanol (right).

provided a more compact and flat molecular configuration of TPE carboxylates within the interlayers. Apart from the amplification of the fluorescence intensity, a red shift of the emission wavelength upon intercalation was observed. The emission wavelength of TPE carboxylates peaks at $465 \mathrm{~nm}$, but shifts to $472 \mathrm{~nm}$ in the case of $\mathrm{Mg}_{2} \mathrm{Al}$-L-TPE. Such a red shift is attributed to a J-type aggregation of TPE carboxylates in the 2D confined space. ${ }^{41-43}$ The fluorescence lifetime of $\mathrm{Mg}_{2} \mathrm{Al}-\mathrm{L}-\mathrm{TPE}$ was investigated using time-resolved luminescence decay analysis (Fig. S9). The decay curves were fitted in a dualexponential form and the data are listed in Table S2. It was found that the life time of $\mathrm{Mg}_{2} \mathrm{Al}$-L-TPE (2.94 ns) is slightly shorter than that of TPE carboxylates (3.10 ns). This is in accordance with the fluorescence spectra as the J-type aggregation of TPE carboxylates in $\mathrm{Mg}_{2} \mathrm{Al}$-L-TPE would facilitate the internal conversion process. ${ }^{15,43}$ Though inferior in life time, the absolute quantum yield of $\mathrm{Mg}_{2} \mathrm{Al}$-L-TPE (23.72\%) is found to be higher than that of TPE carboxylates (16.88\%), which is in proportion to the fluorescence intensity. Another interetign observation arised formt the incorporation of TPE into the gallery of LDHs is the fact that the fluorescent emission was retained even in methanol, which is a good solvent of TPE and typically causes fluorescence quenching (Fig. 6F).

\section{Conclusions}

In conclusion, we have reported here new approaches with general applicability for the intercalation of LDHs using organic acids. The investigated methods, are different from the traditional anion exchange one, are based on the metathesis reaction, where the interlayer carbonates of $\mathrm{LDHs}$ are converted into carbon dioxides by organic acids that are of relatively stronger acidity than carbonic acid. The reaction mechanism has been investigated in detail by taking the intercalation of acetates as an example. Various techniques including GC-MS, powder XRD, solid-state ${ }^{13} \mathrm{C} N M R$, and FT-IR have been adopted to confirm the successful intercalation of acetates using the direct method. SEM, TEM, HRTEM, and AFM have further demonstrated the robustness of the LDH plates upon intercalation. Besides the $\mathrm{Mg}_{2} \mathrm{Al}-\mathrm{L}$, this method has also been applied to a number of LDHs with different sizes and compositions such as $\mathrm{Mg}_{2} \mathrm{Al}-\mathrm{M}, \mathrm{Mg}_{2} \mathrm{Al}-\mathrm{S}, \mathrm{Zn}_{2} \mathrm{Al}-\mathrm{LDHs}, \mathrm{Ni}_{2} \mathrm{Fe}-$ $\mathrm{LDHs}$, and $\mathrm{CO}_{2} \mathrm{Al}-\mathrm{LDH}$. Investigation of the structural and physical properties of the organic acids on the intercalation process revealed that the molecular size of the organic acid plays a key role. Intercalation of large molecules into LDHs employing the direct method is chalenging. Therefore, the stepwise method, using acetate-intercalated LDHs as reactive intermediates, has been proposed for the successful intercalation of organic acids of large molecular size. As a result, a large number of carboxylates, sulfonates, and phosphonates have been incorporated into the galleries of LDHs, demonstrating further the general applicability of these methods on intercalation processes. Finally, a bulky AIE molecule, TPE, has been intercalated into LDHs which led to he formation of a photo-luminescent hybrid material exhibiting increased fluorescence intensity, quantum yield and antiquenching properties when compared with the pure organic TPE counterpart. It is therefore believed the methods proposed here provide fundamentally new routes for the intercalation of LDHs which can facilitate the development of two-dimensional functional hybrid materials. 


\section{Conflicts of interest}

There are no conflicts to declare.

\section{Acknowledgements}

This research was supported by the National Nature Science Foundation of China(U1707603, 21625101, 21521005, U1507102, 21901016), Beijing Natural Science Foundation (2182047) and the Fundamental Research Funds for the Central Universities (XK1802-6, XK1803-05, XK1902, ZY1822, 12060093063).

\section{References}

1 Q. Wang and D. O'Hare, Chem. Rev. 2012, 112, 4124.

2 G. Fan, F. Li, D. G. Evans and X. Duan, Chem. Soc. Rev. 2014, 43, 7040.

3 C. Taviot-Guého, V. Prévot, C. Forano, G. Renaudin, C. Mousty and F. Leroux, Adv. Funct. Mater. 2018, 28, 1703868.

4 J. Wang, L. Zhao, H. Shi and J. He, Angew. Chem. Int. Ed. 2011, 123, 9337.

5 M. Xu and M. Wei, Adv. Funct. Mater. 2018, 28, 1802943.

6 W. Chang, B. Qi and Y.-F. Song, ACS Appl. Mater. Interfaces 2020, 12, 36389.

7 Y. Qin, J. Shi, X. Gong, Z. Tian, P. Zhang and J. Lu, Adv. Funct. Mater. 2016, 26, 6752

8 P. Zhang, Y. Hu, R. Ma, L. Li and J. Lu, J. Mater. Chem. B 2017, 5, 160.

9 R. Liang, R. Tian, L. Ma, L. Zhang, Y. Hu, J. Wang, M. Wei, D. Yan, D. G. Evans and X. Duan, Adv. Funct. Mater. 2014, 24 3144.

10 L. Peng, X. Mei, J. He, J. Xu, W. Zhang, R. Liang, M. Wei, D. G. Evans and X. Duan, Adv. Mater. 2018, 30, 1707389.

11 L. Wu, Z. Hu, G. Chen and Z. Li, Soft Matter 2015, 11, 9038.

12 P. Win, C.-G. Lin, Y. Long, W. Chen, G. Chen and Y.-F. Song, Chem. Eng. J. 2018, 335, 409.

13 S. Miyata, Clays Clay Miner. 1983, 31, 305.

14 N. Iyi, Y. Ebina and T. Sasaki, Langmuir 2008, 24, 5591.

15 W. Shi, M. Wei, D. G. Evans and X. Duan, J. Mater. Chem. 2010, 20, 3901.

16 N. Iyi, Y. Ebina and T. Sasaki, J. Mater. Chem. 2011, 21, 8085.

17 G. Abellán, E. Coronado, C. Martí-Gastaldo, A. Ribera, J. L. Jordá and H. García, Adv. Mater. 2014, 26, 4156.

18 G. Abellán, J. L. Jordá, P. Atienzar, M. Varela, M. Jaafar, J. Gómez-Herrero, F. Zamora, A. Ribera, H. García and E. Coronado, Chem. Sci. 2015, 6, 1949.

19 D. L. Bish, Bull. Miner. 1980, 103, 170.

20 N. Iyi, T. Matsumoto, Y. Kaneko and K. Kitamura, Chem. Mater. 2004, 16, 2926.

21 N. Iyi and T. Sadaki, Appl. Clay. Sci. 2008, 42, 246.

22 N. Iyi and T. Sadaki, J. Colloid Interface Sci. 2008, 322, 237.

23 N. Iyi and H. Yamada, Chem. Lett. 2010, 39, 591.

24 A. Hayashi and H. Nakayama, Chem. Lett. 2011, 40, 276.

25 N. Iyi, H. Yamada and T. Sasaki, Appl. Clay Sci. 2011, 54, 132.

26 D. Yan, J. Lu, J. Ma, M. Wei, S. Qin, L. Chen, D. G. Evans and X. Duan, J. Mater. Chem. 2010, 20, 5016.

27 P. Zhao, X. Liu, W. Tian, D. Yan, X. Sun and X. Lei, Chem. Eng. J. 2015, 279, 597.

28 R. Gao and D. Yan, Chem. Sci. 2017, 8, 590.

29 S. Liu, L. Cui, Z. Peng, J. Wang, Y. Hu, A. Yu, H. Wang, P. Peng and F.-F. Li, Nanoscale 2018, 10, 21764.

30 J. Lee, S. Rhee and D.-Y. Jung, Chem. Commun. 2003, 2740.

31 J.-M. Oh, S.-H. Hwang and J.-H. Choy, Solid State Ionics 2002, 151, 285.
32 A. Corma, V. Fornés, R. M. Martín-Aranda and F. Rey, J. Catal. 1992, 134, 58.

33 T. Hibino, Y. Yamashita, K. Kosuge and A. Tsunashima, Clays Clay Miner. 1995, 43, 427.

34 Y. Kuroda, Y. Miyamoto, M. Hibino, K. Yamaguchi and N. Mizuno, Chem. Mater. 2013, 25, 2291.

35 H. Zhou, Q. Ye, X. Wu, J. Song, C. M. Cho, Y. Zong, B. Z. Tang, T. S. A. Hor, E. K. L. Yeow and J. Xu, J. Mater. Chem. C 2015, 3, 11874.

36 G. V. Manohara, P. V. Kamath and W. Milius, J. Solid State Chem. 2012, 196, 356

37 H. C. Greenwell, W. Jones, D. N. Stamires, P. O'Connor and M. F. Brady, Green Chem. 2006, 8, 1067.

38 A. Aguzzi, V. Ambrogi, U. Costantino and F. Marmottini, J. Phys. Chem. Solids 2007, 68, 808.

39 S. Tamesue, K. Yasuda and T. Endo, ACS Appl. Mater. Interfaces 2018, 10, 29925.

40 R. Hu, N. L. C. Leung and B. Z. Tang, Chem. Soc. Rev. 2014, 43, 4494.

41 J. Bauer, P. Behrens, M. Speckbacher and H. Langhals, Adv. Funct. Mater. 2003, 13, 241.

42 S. Gago, T. Costa, J. S. de Melo, I. S. Gonçalves and M. Pillinger, J. Mater. Chem. 2008, 18, 894.

43 D. Yan, J. Lu, M. Wei, D. G. Evans and X. Duan, J. Phys. Chem. B 2009, 113, 1381. 